\title{
Retórica na construção de realidades na segurança pública: abordagens dos sistemas de Minas Gerais e São Paulo
}

\author{
Jeferson A. Fonseca \\ Cepead/Face/UFMG \\ Luciano Z. Pereira \\ Faculdades Novos Horizontes \\ Carlos A. Gonçalves \\ Fumec e UFMG
}

\begin{abstract}
A proposta deste artigo é apresentar uma comparação entre duas ações produzidas na gestão pública em segurança: (i) a difusão do modelo da nova gestão pública como substituto "natural" da teoria da burocracia e (ii) a implantação de "novas estratégias e técnicas de gestão" que se deu de modo praticamente concomitante à ação anterior. A demarcação metodológica consistiu em abordagem de natureza qualitativa, com base na pesquisa descritiva, tendo por método o estudo de caso. Os resultados obtidos mostram que, no que tange à possível substituição da teoria da burocracia pelo modelo da nova gestão pública, isso não encontra sustentação na realidade. Também, não se verificam transformações que possam confirmar o esgotamento da teoria da burocracia e o surgimento de uma nova teoria, como preconizam os defensores do modelo da nova gestão pública.
\end{abstract}

Palavras-chave: administração pública; segurança pública; estruturas organizacionais.

Retórica y realidad en la seguridad pública: estudio de las estructuras de los sistemas de seguridad pública en los estados de Minas Gerais y São Paulo

El propósito de este trabajo es presentar una comparación entre dos acciones que se producen en la gestión de la seguridad pública: (i) la difusión del modelo de la nueva gestión pública como reemplazo "natural" de la teoría de la burocracia y (ii) la implementación de "nuevas estrategias y técnicas de gestión" que se produjeron casi simultáneamente a la acción anterior. La delimitación metodológica consistió en enfoque cualitativo, basado en una investigación descriptiva, cuyo método es de estudio de caso. Los resultados obtenidos muestran que, en cuanto a la posible sustitución de la teoría de la burocracia por el modelo de la nueva gestión pública, esto no tiene fundamento en la realidad. Además,

DOI: http://dx.doi.org/10.1590/0034-7612127741

(c) BY-NC

Artigo recebido em 7 dez. 2013 e aceito em 19 set. 2014. 
no hay cambios que pueden confirmar el agotamiento de la teoría de la burocracia y el surgimiento de una nueva teoría, como preconizan los defensores del modelo de la nueva gestión pública.

Palabras clave: administración pública; la seguridad pública; estructuras organizativas.

Rhetoric in the construction of realities in public security: approaches of the systems in the states of Minas Gerais and São Paulo

The objective of this article is to present a comparison between two actions produced in the public management field of security: (i) the diffusion of the new public management model as a "natural" substitute for the bureaucracy theory and (ii) the implantation of "new management strategies and techniques", which happened almost at the same time as the previous action. The methodological demarcation consisted of a qualitative approach, based on the descriptive research and case study method. The results obtained show that a possible substitution of the bureaucratic theory for the new public management model does not sustain in reality. Also, it was also verified that there are no transformations that can confirm the exhaustion of bureaucracy theory and the emerging of a new theory, as professed by members of the new public management model.

KEYWORDs: public administration; public security; organizational structures.

\section{Introdução}

A introdução de mudanças funcionais e estruturais na área de segurança pública em suas várias esferas é comunicada de forma recorrente. Além de propostas de mudanças estruturais concomitantes às funcionais, na esperança de que a forma siga a função, o agente público reproduz a ação na administração pública e, de modo específico, na segurança pública, buscando propor novas diretrizes e novos mecanismos de gestão, que alcancem objetivos estabelecidos pelas exigências sociais contemporâneas. Isso, sem dúvida, demanda atender e/ou contrariar interesses de stakeholders internos e externos, criando resistências culturais e uma sentida anomia na "máquina estatal" orientada a esse fim e em todos os sistemas de segurança pública dos estados-membros brasileiros.

Nesse prisma, difratam-se diferentes olhares do modelo da nova gestão pública, que é apresentado por Abrucio (2006) como legitimador do processo de transformação. Percebe-se, no caso brasileiro, de acordo com Costa e Landim (2007), a importância primária do Plano Diretor da Reforma do Aparelho do Estado (PDRAE) (Brasil, 1995), que teve a função de estabelecer a modernização administrativa dos governos subnacionais, o que estimulou a adoção de novos modelos de gestão pública, o intercâmbio de experiências e a ampliação das "melhores práticas" em todos os níveis de governo, sem contudo apresentar ao isomórfico para benchmarking. Especificamente no que tange à segurança pública, foi proposta a criação de instrumentos normativos, em nível tanto federal quanto estadual (Minas Gerais, 2007).

De modo a alcançar a almejada segurança pública ideal, conforme estabelecido em metas e indicadores de "bem-estar social", as "melhores práticas" foram consolidadas e imputadas em grande parte a mecanismos normativos criados para que a segurança pública 
fosse estendida a todos os cidadãos. Nesse sentido, constituem instrumentos de maior amparo legal-institucional: no âmbito da União - Constituição da República Federativa do Brasil (Brasil, 1995), Plano Nacional de Segurança Pública (PNSP) (Brasil, 2003), Força Nacional de Segurança Pública (Brasil, 2004) e Programa Nacional de Segurança Pública com Cidadania (Brasil, 2007); no âmbito dos estados-membros da federação — as respectivas constituições estaduais e os planos estaduais de segurança pública e/ou de defesa social. ${ }^{1}$ Em relação ao principal documento normativo citado, a Constituição da República Federativa do Brasil (Brasil, 1988), consta em seu bojo o seguinte:

\section{[...] CAPÍTULO III.}

\section{DA SEGURANÇA PÚBLICA.}

Art. 144. A segurança pública, dever do Estado, direito e responsabilidade de todos, é exercida para a preservação da ordem pública e da incolumidade das pessoas e do patrimônio, através dos seguintes órgãos:

$\mathrm{I}-[\ldots]$

IV - polícias civis;

$\mathrm{V}$ - polícias militares e corpos de bombeiros militares.

$\S 1^{\circ}[\ldots]$

$\S 4^{\circ}$ - às polícias civis, dirigidas por delegados de polícia de carreira, incumbem, ressalvada a competência da União, as funções de polícia judiciária e a apuração de infrações penais, exceto as militares.

$\S 5^{\circ}$ — às polícias militares cabem a polícia ostensiva e a preservação da ordem pública; [...].

$\S 6^{\circ}$ - As polícias militares e corpos de bombeiros militares, forças auxiliares e reserva do Exército, subordinam-se, juntamente com as polícias civis, aos governadores dos estados, do Distrito Federal e dos territórios.

$\S 70[\ldots]$

$\S 8^{\circ}$ - Os municípios poderão constituir guardas municipais destinadas à proteção de seus bens, serviços e instalações, conforme dispuser a lei.

$\S 9^{\circ}[\ldots]$ (itálico nosso).

Pelo exposto, como textualmente enunciado, a segurança pública está fundamentada principalmente na Constituição da República Federativa do Brasil (Brasil, 1988), que discipli-

\footnotetext{
${ }^{1}$ Conceitualmente, a prestação de serviços de defesa civil e de segurança pública, entre outras atividades, é o que se denomina Defesa Social. Defesa Civil é o conjunto de medidas que visam a prevenir e a limitar os riscos e perdas a que estão sujeitos a população, os recursos públicos e os bens materiais de toda espécie, tanto por agressão externa quanto em consequência de calamidades e desastres naturais (Brasil, 2009). Ressalte-se que neste artigo se tratará somente sobre o tema Segurança Pública.
} 
na as funções e missões de cada um dos órgãos: Polícia Federal, Polícia Rodoviária Federal e Polícia Ferroviária Federal, no âmbito da União; polícias civis, polícias militares e corpos de bombeiros militares, no âmbito dos estados-membros; e guardas municipais, no âmbito dos municípios, como representado estruturalmente na figura 1.

Figura 1

Distribuição dos órgãos de segurança pública, segundo o nível federativo

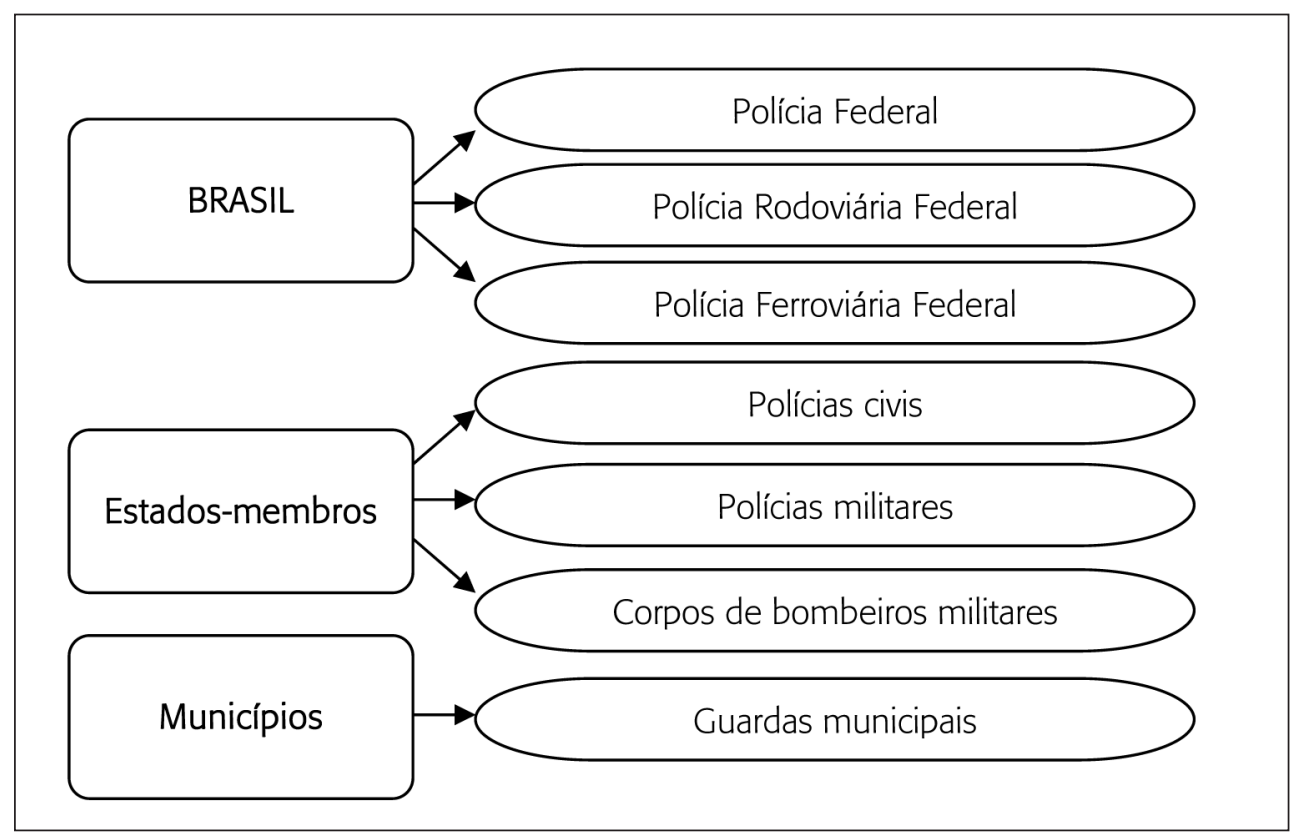

Fonte: Dados da pesquisa, com base no art. 144, da CRFB (Brasil, 1988).

Nesse aglomerado de sistemas complexos concebidos pelos gestores, em sua arquitetura orientada para a geração do grau de "bem-estar social e de segurança", florescem muitos conflitos ideológicos, de gestão e de tratamento, bem como casuísmos, na aplicação, interpretação e operacionalização do objeto "segurança pública", o que torna o sistema resultante "anômico", ineficiente. Ainda, mesmo que haja proposta institucional "bem-intencionada" do sistema de governança, na tentativa ideal de unificação da estratégia, expressa no conteúdo dos documentos e nos discursos dos agentes dos órgãos de segurança pública, percebem-se fragilidades em sua efetividade operacional.

Nessa perspectiva, nota-se um berçário de pensar e agir contraditórios, idiossincráticos e imanentes aos sistemas. Disso toma-se como necessidade a pesquisa das interações praticadas dentre e entre os agentes interpretantes e gestores do sistema de segurança pública, bem como a identificação dos paradoxos e contradições que impedem que os atuais modelos de segurança pública de estados-membros brasileiros alcancem a efetividade segundo as "melhores práticas". Assim, tem-se a seguinte questão orientadora deste estudo: quais os modelos 
estruturais e funcionais de segurança pública adotados em Minas Gerais e São Paulo e como são percebidos pelos agentes de seus respectivos sistemas?

Vale salientar que a pesquisa delimita-se espacialmente nos estados-membros de Minas Gerais e de São Paulo, por possuírem as maiores populações e contingentes de servidores dos sistemas de segurança pública do Brasil.

A partir da problematização e do problema de pesquisa, o objetivo da pesquisa é identificar e analisar os modelos estruturais e funcionais de segurança pública adotados nos estados de Minas Gerais e de São Paulo, bem como a percepção de seus agentes quanto aos modelos, de forma a contribuir para o entendimento das ações estruturantes que expliquem e justifiquem os modelos adotados.

A temática estudada é importante em termos acadêmicos, institucionais e sociais por sua natureza intrínseca, já que afeta e trata de fatores relativos à nossa segurança e ao "bemestar social" em aspectos amplos.

Quanto à dimensão acadêmica, é importante o avanço dos estudos em relação aos problemas da segurança, criminalidade e violência, possibilitando elementos empíricos que possam contribuir com o avanço de estudos nessa área. Ademais, apesar dos consideráveis avanços no debate e do substancial aumento recente de pesquisas, não há uma investigação sistemática sobre a polícia, na perspectiva das ciências administrativas e da gestão, e grande parte dos estudos realizados não inclui a abordagem empírica, limitando-se apenas à pesquisa bibliográfica e à abordagem descritiva. Dessa forma, este estudo é uma contribuição na direção prescritiva, analisando a reforma dos organismos da segurança pública, principalmente quanto às suas estruturas e às relações entre e dentre os órgãos componentes dos sistemas de segurança pública.

Quanto à dimensão institucional, sabe-se que os órgãos componentes dos respectivos sistemas de segurança pública são em sua maioria centenários, possuindo grandes estruturas, tanto centrais, quanto capilares, bem como executando inúmeras atividades, algumas delas muito diferentes de suas missões constitucionais. Por outro lado, há demandas da sociedade no sentido de uma melhor qualidade de prestação de serviços, por parte das citadas organizações, de uma maior aproximação com o cidadão-usuário e, até mesmo, de uma reforma dos órgãos, com vistas a torná-los mais "enxutos”, ágeis, transparentes, confiáveis e focados em suas atividades específicas.

Quanto à dimensão social, entende-se que são vários os fatores que justificam esta pesquisa, já que os órgãos componentes dos sistemas de segurança pública dos estadosmembros do Brasil são essencialmente burocráticos e têm procurado mostrar, aos respectivos cidadãos-usuários, que estão em processo de mudança. Busca-se uma administração gerencial, com o fito de se tornarem cada vez mais aptos a executar suas missões com eficácia, de forma a garantir as seguranças objetiva e subjetiva dos cidadãos. No país, isto ocorre em função de se viver um clima de desconfiança quanto à competência dos órgãos mencionados para o cumprimento de suas missões constitucionais, bem como em função da necessidade de se reduzir custos e se buscar a prestação de serviços de segurança pública de qualidade. 
Este artigo está estruturado em quatro capítulos, incluindo esta introdução. No capítulo 2 aborda-se o arcabouço teórico, discorrendo-se sobre as teorias que tratam da burocracia, estrutura das organizações, nova gestão pública, administração pública e segurança pública. No capítulo 3, detalham-se os caminhos metodológicos definidos para sustentar a análise e discussão dos dados e apresentam-se os resultados. No capítulo 4, apresentam-se as considerações finais, resgatando-se as principais discussões levantadas no decorrer do artigo, bem como apontando as limitações do estudo e sugestões para futuras pesquisas.

\section{Arcabouço teórico}

Para consubstanciar a pesquisa discorre-se sobre: teoria da burocracia, estrutura das organizações, nova gestão pública, administração pública e segurança pública.

\subsection{Teoria da burocracia}

Conforme Weber (1967:264), burocracia “é o meio de transformar uma 'ação comunitária' em uma 'ação societária' racionalmente organizada". Essa afirmação baseia-se na burocracia plenamente estabelecida que, para o autor, é o instrumento de "socialização" das relações de poder, em especial para quem controla o aparato burocrático. Hall (1966), ao tratar sobre o mesmo tema, afirma:

O conceito de Burocracia é aqui concebido como uma série de dimensões, cada qual na forma de um contínuo. (...) Os estudiosos das organizações, desde Weber até o presente, têm utilizado o modelo burocrático como base para a conceitualização de sistemas de inter-relações em organizações. Essa aceitação do modelo burocrático tem servido como ponto de partida para estudos de desenvolvimento e modificação da estrutura organizacional, do lugar do indivíduo dentro dessa estrutura e de vários problemas afins. (Hall, 1966:28-29, itálico nosso)

Como se vê, a existência da burocracia está ligada a um continuum, não sendo descrita simplesmente em termos de presença ou ausência. Acrescenta-se que esse ponto pode ser desenvolvido "na afirmação de que a burocracia é uma forma de organização que existe ao longo de uma série de contínuos ou dimensões" (Hall, 1966:31).

Nesta pesquisa, a proposta de complementar a burocracia weberiana com os estudos sobre as dimensões burocráticas apoia-se na ideia de Hall (1966:29), ao mostrar que Weber descreveu as organizações burocráticas a partir de um prisma dimensional, ou seja, elencando vários atributos organizacionais específicos. Essas dimensões, atributos ou características (Udy Jr., 1966; Merton, 1968) servem como base para delineações subsequentes da estrutura burocrática, sendo: divisão do trabalho, hierarquia de autoridade, limitação da autoridade de cada cargo, membros tecnicamente competentes, normas extensivas, salário e 
promoção baseados na competência técnica e, finalmente, separação entre administração e propriedade (Hall, 1984:38).

Todavia, verifica-se, conforme salienta Merton (1968:274), que a sociedade costuma dar grande destaque, não ao sistema burocrático em si, mas principalmente às imperfeições da burocracia, "tal como se sugere pelo fato desse 'horrível hibridismo', a palavra burocrata, ter-se tornado um epíteto, um Schimpfwort - uma palavra pejorativa".

O posicionamento relacionado com as imperfeições da burocracia é respaldado na análise de Hall (1984), quando afirma que as disfunções pessoais e organizacionais foram reconhecidas na minuciosa discussão de Merton (1968) sobre a personalidade burocrática. Acrescenta que nas organizações burocráticas as regras se tornam mais importantes do que os objetivos para cuja consecução foram criadas para contribuir, de sorte que a "organização se torna muito rígida e tem dificuldades em lidar com os clientes e com outros aspectos do ambiente" (Hall, 1984:74).

No caso das organizações aqui tratadas, as regras são essenciais ao seu funcionamento, havendo previsão legal estabelecida, inclusive, no texto constitucional, em especial nos arts. 144 e 37 (Brasil, 1988). Portanto, essas organizações encontram-se "amarradas" às normas e regulamentos (Fonseca, 2013).

Gouldner (1966) distingue cinco características principais relacionadas com a citada "regra": permite o controle à distância; constitui uma tela e uma proteção ao reduzir as relações interpessoais; restringe a arbitrariedade dos superiores e legitima a sanção; possibilita a apatia, ou seja, um comportamento de retração que se contenta com a mera aplicação das regras; e permite, por isso, a negociação com a hierarquia. Crozier (1981), ao tratar da burocracia francesa, afirma que sua "racionalidade" reside no fato de permitir a gerência de questões afetivo-emocionais suscitadas pela confrontação, intrínseca à cooperação dos indivíduos de uma organização, em razão da dependência, poder e arbitrariedade das pessoas.

Por seu turno, Perrow (1972) aponta três acusações contra a burocracia: é impermeável a mudanças novas e inovações, é rígida e é vagarosa. Todavia, existem fundamentações que "jogam por terra" as três acusações elencadas. Em relação às mudanças, estas normalmente custam caro, bem como resistir a elas, fazendo com que a argumentação no sentido de que a modificação se torne insuperável é, sobretudo, um modo inteligente para que as organizações, principalmente de produção em grande escala, possam cumprir seus objetivos. Agir de maneira rápida e mudar constantemente os modos de trabalhar significa, também, aumentar os custos operacionais e, nesse prisma, entende-se ser bastante razoável supor que o ambiente não é, de modo geral, tão instável de sorte que a maior parte das oscilações pode e deve ser ignorada. Finalmente, o funcionamento de várias organizações é lento em virtude de que, com o fito de reduzir os custos e a insegurança, são estabelecidos prazos de produção suficientemente longos.

Portanto, as organizações burocráticas são caracterizadas por dimensões, em variados graus, que servem como fundamentos para delineamento de suas estruturas respectivas. No caso das organizações de segurança pública dos estados-membros brasileiros, essas dimensões ou atributos são facilmente identificados, com destaque para: hierarquia de autorida- 
de, limitação da autoridade de cada cargo, divisão do trabalho e normatização extensiva (Fonseca, 2013).

Em suma, segundo afirmação de Fonseca (2013), as organizações de segurança pública dos estados-membros do Brasil, por serem essencialmente burocráticas, valorizam sobremaneira o uso de normas, regras e regulamentos, que se tornam mais importantes do que os objetivos para cuja consecução foram criadas para contribuir. Esta excessiva normatização faz com que os órgãos mencionados se tornem muito rígidos e passem a ter dificuldades em lidar com os cidadãos-usuários e demais aspectos do contexto ambiental. Ademais, de modo geral, as organizações burocráticas se caracterizam pela sua estruturação, que varia de acordo com os ambientes nos quais se situam, as estratégias escolhidas, os tamanhos e as tecnologias utilizadas.

\subsection{Estrutura das organizações}

Ranson, Hinnings e Greenwood (1980:3, itálico nosso) conceituam estrutura organizacional como "um meio complexo de controle que é continuamente produzido e recriado em interação e que, ainda assim, modela essa interação: as estruturas são constituídas e constitutivas". As estruturas são constitutivas já que geram outras ações, de sorte que as pessoas atendem às normas e decisões organizacionais; as estruturas são constituídas já que as distribuições de poder estão sujeitas a mudanças, na medida em que os grupos e indivíduos obtêm ou perdem poder no decorrer do tempo (Leite, Albuquerque e Kniess, 2010). Aqui, opta-se pela adoção desse conceito, pois sua amplitude abrange as estruturas tradicionais ou mecânicas e também as estruturas modernas ou orgânicas, de modo não restritivo, com ênfase no ser humano.

É relevante esclarecer que a estrutura organizacional, na visão de Hall (1984), atende a três funções básicas: desenvolvimento de produtos e/ou serviços e atingimento das metas organizacionais; minimização ou regulamentação da influência das variações individuais sobre a organização, a partir da imposição das estruturas, com o fito de assegurar que as pessoas se conformem às exigências "organizacionais", e não o inverso; e locus em que o poder é exercido, no qual as decisões são tomadas e no qual são executadas as atividades inerentes à organização.

Saliente-se que as organizações possuem três atributos fundamentais, denominados características estruturais: (1) centralização, que possui graus variáveis, de muito baixo a muito alto, de sorte que quanto melhor for considerada a qualidade da cúpula diretiva da organização mais alta é a descentralização de autoridade nessa mesma organização, sendo o inverso também verdadeiro; (2) complexidade, que ocorre a partir da dispersão geográfica e da extensão da hierarquia; contudo, isso faz com que as organizações encontrem obstáculos quanto a fatores como coordenação e controle, óbices esses que somente podem ser superados pela existência de canais de comunicações efetivos entre as várias unidades organizacionais; e (3) formalização, que varia de maneira semelhante à centralização; em algumas áreas as normas e procedimentos são explicitados nos mínimos detalhes, enquanto em outras áreas praticamente não há normatização (Hall, 1984). 
Em suma, estrutura organizacional refere-se à distribuição das pessoas nos níveis organizacionais, que influenciam seus respectivos papéis, a partir da divisão do trabalho e dos variados níveis hierárquicos. Sua amplitude abrange as estruturas tradicionais ou mecânicas e também as estruturas modernas ou orgânicas, de modo não restritivo, com ênfase nas pessoas e nas complexas inter-relações existentes. Conforme afirmação de Fonseca (2013), no período contemporâneo, acredita-se que as estruturas das organizações devam ser transformadas, a partir da descentralização de poder para a "ponta da linha", da delegação de autoridade para os gestores locais e da horizontalização organizacional com a redução de níveis hierárquicos, propostas estas apresentadas pelos defensores do modelo gerencialista.

\subsection{Modelo da nova gestão pública}

Na burocracia nota-se a predominância das chamadas "práticas progressistas": emprego vitalício, salários regulares pagos independentemente do trabalho realizado, autonomia do poder público e monopólio ou "reserva de mercado". Essas práticas "podem ser interpretadas como uma forma em que os burocratas e os profissionais se esquivam dos rigores da competência mercantil e da subordinação real aos controladores políticos" (Hood, 1994:473, tradução nossa). De modo a corrigir esses "desvios" é que surgiu a nova gestão pública (NGP), sendo umas de suas principais propostas a "diminuição das diferenças organizativas entre os setores privado e público, com o fito de reduzir a ineficiência dos serviços públicos", conforme Hood (1994:473, tradução nossa), determinando que os métodos de funcionamento dos entes estatais devem ser modificados, retirando o foco das regras gerais e direcionando-o para os resultados.

Aucoin (1990) mostra que o processo generalizado de reforma da gestão pública, do qual a administração pública tem sido protagonista nas últimas décadas, tem provocado tensões que conduzem à elaboração de respostas políticas. No contexto destas tensões, dois conjuntos de ideias influenciam o desenho dos sistemas de governo e de gestão. O primeiro tem sua gênese no modelo da Public Choice Theory, centrando-se na necessidade de restabelecer o domínio do governo sobre a burocracia. O segundo, conhecido como New Public Management, tem seu foco na necessidade de restabelecer o domínio dos princípios gerenciais sobre a burocracia.

Corroborando o exposto, Abrucio (2006) afirma que o modelo gerencial da administração pública inglesa teve sua gênese sustentada em três visões surgidas entre as décadas de 1970 e 1980: (1) Managerialism ou gerencialismo puro, visão embasada no conceito de produtividade, em que se buscou a redução e a otimização dos gastos públicos, em um contexto que tinha como eixo primário a busca pela eficiência, com clara definição das responsabilidades dos funcionários, dos objetivos organizacionais e de maior consciência em relação ao valor dos recursos públicos; (2) Consumerism, visão alicerçada na busca constante pela efetividade e pela qualidade, mediante a introdução da perspectiva da qualidade, com uma estratégia voltada para a satisfação dos cidadãos usuários/consumidores, a partir de medidas 
que tornavam o poder público mais ágil, competitivo e enxuto: descentralização administrativa, criação de opções de atendimento como incentivo à competição entre organizações públicas e adoção de um novo modelo contratual; e (3) Public service orientation, visão baseada na ideia-chave da conjugação entre a accountability e o binômio justiça/equidade e que, embora mantendo uma forte sustentação crítica ao Managerialism e ao Consumerism, não descartou as ideias desenvolvidas por ambas as visões.

Posteriormente, o modelo de reestruturação do Estado e da administração pública empreendido no Reino Unido tornou-se referência para outros países. Entretanto, é importante considerar:

Que a adesão às medidas neoliberais britânicas não ocorreu de uma forma "mecânica": a maior contribuição do thatcherismo às reformas do final do Século XX foi a criação de um discurso apropriado para as reestruturações empreendidas, além do fortalecimento de uma gama de exemplos para as práticas que se pretendia implementar. (Paula, 2005:48, negrito nosso)

Reforça-se que o modelo da NGP propõe a diminuição das diferenças organizativas entre os setores privado e público, tendo o objetivo de reduzir a ineficiência dos serviços públicos, a partir da mudança do foco, que passa das regras gerais para os resultados. Nesse prisma, seus pressupostos dão maior ênfase: na adoção de práticas do setor privado no setor público; na competição formal, tanto entre organizações do setor público, quanto entre organizações públicas e privadas; no controle das organizações públicas, mediante um conjunto preestabelecido de mensuração de resultados; na desagregação das organizações públicas em unidades separadas e autônomas; no estabelecimento de padrões de funcionamento explícitos e mensuráveis, em termos de alcance, nível e conteúdo dos serviços a serem providos; e na gestão direta, ou seja, a descentralização de poder e autoridade para a gerência da "ponta da linha", utilizando-se de ferramentas como o controle ativo e o aumento de poder discricionário (Hood, 1994).

Portanto, de modo geral tem-se concebido a reorganização da estrutura do setor público a partir da desconcentração de autoridade para o âmbito local, em suas respectivas áreas de gestão, o que é pontuado como condição suficiente. Conforme Aucoin (1990), em todo o mundo as organizações públicas estão se dividindo em unidades menores e independentes, substituindo a tradicional hierarquia burocrática, tendência esta que parece ser irreversível, e a principal mudança talvez se refira ao convencimento de que as burocracias públicas mastodônticas não são a melhor e nem a mais eficaz forma para organizar os serviços do Estado.

Fica patente, então, a existência do "paradoxo" burocracia versus nova gestão pública. De acordo com os pressupostos e atributos desta última, acredita-se que os arranjos organizacionais burocráticos foram bem-sucedidos durante um longo período, principalmente no que tange à garantia de empregos, de estabilidade econômica, de justiça e equidade, de segurança e de serviços padronizados. Todavia, atualmente os mesmos arranjos já não encontram respaldo no contexto sócio-organizacional, o que motiva a necessidade de uma ampla reforma (Fonseca, 2013). 
Portanto, há premente necessidade de transformação da administração pública, que deverá ter foco nos resultados e na efetividade dos serviços públicos, a partir de mecanismos como descentralização de poder e autoridade aos gestores, bem como divisão e horizontalização das organizações, de modo que ocorra a real aproximação entre o Estado e o cidadãousuário (Fonseca, 2013).

\subsection{Administração pública}

A nova gestão pública e a administração burocrática são sistemas que contrastam entre si, conforme afirmação de Farnham e Horton (1996). Esses autores fundamentam sua assertiva nos seguintes pressupostos: os objetivos da burocracia tendem a ser fixados em termos gerais e raramente são revistos ou mudam, enquanto nos sistemas da NGP os objetivos estão claramente definidos e são passíveis de ajuste; o mais relevante critério de sucesso na burocracia consiste em evitar erros e fazer as coisas de modo certo, enquanto nos sistemas da NGP o critério de sucesso consiste em atingir os objetivos, normalmente expressos em termos quantitativos; o uso eficiente e econômico dos recursos é secundário na burocracia, mas de primeira importância na criação de sistemas efetivos de gestão na NGP; a burocracia tende a ter uma cultura na qual as responsabilidades são definidas de modo preciso e, naqueles em que existem, as delegações são limitadas, diferentemente do sistema da NGP, em que há uma cultura de tarefa e maior delegação; na burocracia as estruturas tendem a ter hierarquias alongadas e os problemas são reportados aos níveis superiores dessa hierarquia, enquanto na NGP as estruturas hierárquicas são mais achatadas e a competência na tomada de decisões está na "ponta da linha"; e o papel do administrador na burocracia consiste, principalmente, em servir de árbitro e de intérprete das regras, o que contrasta com o gestor na NGP, que é protagonista, procurando oportunidades, buscando por recursos e tomando iniciativas (Farnham e Horton, 1996).

Bresser-Pereira (2001), ao tratar das diferenças entre a administração pública burocrática e o modelo da nova gestão pública, preconiza que:

Na Administração Pública Burocrática, as principais preocupações em matéria de governança eram aquelas ligadas à ordem social e à eficácia administrativa (...) [Na Nova Gestão Pública] supõe-se que a estabilidade política e a eficácia do Estado na aplicação da lei tenham sido razoavelmente alcançadas: as maiores preocupações políticas são agora aquelas que dizem respeito à responsabilização democrática e à eficiência administrativa — ou seja, transpor para os serviços públicos a eficiência econômica que os mercados asseguram à produção de bens e serviços, mantendo ao mesmo tempo seu caráter público. (Bresser-Pereira, 2001:15)

No mesmo sentido, Jones e Thompson (2000:44) entendem que é "válido supor que houve um momento em que as burocracias foram relativamente efetivas". Assim, os arranjos organizacionais burocráticos foram bem-sucedidos durante um longo período, principalmente 
no que tange à garantia de empregos, estabilidade econômica, justiça e equidade, segurança e serviços homogêneos — "de tamanho único" - , "requeridos ao longo do período de desenvolvimento da infraestrutura governamental, desde o final do século passado [século XIX] até meados dos anos 60" (Osborne e Gaebler, 1992:14). Todavia, atualmente os mesmos arranjos já não encontram respaldo no contexto social e organizacional, o que motiva a necessidade de uma ampla reforma.

Nessa perspectiva, em relação ao processo de reforma gerencial, o argumento apresentado por Bresser-Pereira (2009) é que esse não deve ser visto como um rompimento radical com a burocracia, mas ao contrário, a administração pública gerencial deve ser construída sobre a administração pública burocrática, baseada na existência de um serviço público profissional e competente, com a combinação de princípios gerenciais e burocráticos variados, conforme as necessidades de cada setor.

Contudo, há pesadas críticas ao modelo da nova gestão pública, de sorte que Pollitt e Bouckaert (2002:5) esclarecem que, por se sentirem livres das inibições científicas da academia, a avaliação das reformas de gestão - que é quase impossível de ser realizada, por variadas razões - normalmente é "feita" por consultores de gestão, gurus e políticos. Dentre as razões apontadas pelos autores como dificultadoras da avaliação das reformas destacam-se: as unidades de análise, que "sofrem com os problemas metodológicos, já que muitas reformas são amplamente 'editadas' e 'traduzidas', quando transferidas de um contexto para outro" (Pollitt e Bouckaert, 2002:7); as unidades de significado, em que os "aspectos retóricos e culturais parecem desempenhar um papel importante em várias reformas do setor público", mas têm sido ignorados ou negligenciados pelas abordagens convencionais de avaliação (Pollitt e Bouckaert, 2002:8); a escassez de dados essenciais, já que se vê a "maioria dos programas de reforma serem anunciados e implementados sem que nenhum plano de avaliação sistemática e independente seja apresentado" (2002:9); os critérios múltiplos e interligados — economia, processos, eficiência, eficácia, capacidade dos sistemas administrativos e tipos ideais - em que, ao se "dar maior importância a um, pode-se estar comprometendo a performance do outro" (Pollitt e Bouckaert, 2002:11-13); o caráter imponderável da mudança, sendo preponderante "questionar se as 'novas práticas' realmente mudaram os resultados. (...) Podem existir vantagens em se dizer uma coisa e fazer outra", de sorte que a "informação a respeito dos resultados (...) é normalmente inexistente, ou difícil de encontrar" (Pollitt e Bouckaert, 2002:13-14).

Em suma, para instrumentalizar a efetiva participação/envolvimento dos cidadãos-usuários é essencial que ocorra a descentralização de poder e de estruturas nas e das organizações. Sendo o Brasil um país continental federativo, em que os estados-membros e seus respectivos municípios não possuem autonomia legal e financeira, pelo contrário, são altamente dependentes da União, nem todas as modificações previstas pelos teóricos da nova gestão pública são possíveis de serem efetivadas. Contudo, decisões como transformar unidades localizadas nos vários municípios em órgãos semiautônomos, nos moldes das unidades estratégicas de negócios, são perfeitamente viáveis. Com essa maior autonomia, facilita-se a participação dos cidadãos e o seu maior envolvimento com a segurança pública (Fonseca, 2013). 
Neste artigo a análise pauta-se, também, nesta retórica apresentada pelos autores, quando da análise documental e, principalmente, quando das entrevistas com os agentes dos sistemas de segurança pública.

\subsection{Sistema de segurança pública}

Conforme apresentado na figura 1 e de acordo com o art. 144 da Constituição da República Federativa do Brasil (Brasil, 1988), os sistemas de segurança pública estão vinculados a cada um dos entes federativos brasileiros. Estando, pois, subordinados ao Poder Executivo, via de regra, existem secretarias de Estado que congregam os órgãos componentes do respectivo sistema de segurança pública, sendo exemplos a Secretaria Nacional de Segurança Pública (Senasp) e as secretarias estaduais de segurança pública/defesa social (Sesp/Seds). Portanto, para Fonseca (2013), as mencionadas secretarias, polícias e corpos de bombeiros integram, per si e no todo, a arquitetura dos sistemas de segurança pública.

Autores como Paixão (1981), Costa (2008) e Lima e Proglhof (2013) mostram que a arquitetura organizacional modela os processos por meio dos quais decisões são tomadas e executadas, o que, por sua vez, influencia fortemente a competência dos governos ao implementar políticas públicas de segurança.

Conforme apresentado por Fonseca (2013), São Paulo tem seu sistema de segurança pública abarcado pela Secretaria de Negócios da Segurança Pública (Sesp), diretamente ligada ao governador do Estado, à qual se subordinam: Polícia Civil (PCSP), Superintendência de Polícia Técnico-Científica (SPTC) e Polícia Militar (PMESP), estando vinculada a esta última o Corpo de Bombeiros Militar.

De maneira distinta do caso paulista, em Minas Gerais cada um dos órgãos integrantes do sistema de segurança pública está diretamente subordinado ao governador do Estado, apesar de somente a Secretaria de Estado de Defesa Social (Seds) ser estruturada como Secretaria de Estado, de acordo com Fonseca (2013). No entanto, todas as demais organizações — Polícia Civil (PCMG), Polícia Militar (PMMG) e Corpo de Bombeiros Militar (CBMMG) — mantêm acesso direto ao chefe do Executivo.

Essa configuração "fragmentada" do sistema de segurança pública de Minas Gerais constitui barreira à viabilização de política pública consistente de combate à criminalidade. Neste sentido, a "ausência de articulação do aparato organizacional sob a responsabilidade do executivo estadual tem constituído um foco crônico de disjunção do sistema e consequentemente afetado a competência governamental para lidar com a manutenção da ordem pública" (Batitucci, Ribeiro e Sapori, 2002:214). Portanto, tem prevalecido o caráter segmentado das intervenções públicas, com cada organização ocupando espaço delimitado de policymaking em suas respectivas esferas de ação, o que impossibilita a efetivação de uma política de segurança pública como conjunto de intervenções minimamente coordenadas, de sorte que: 
A frouxa articulação nessa área de atuação governamental se expressa nos níveis de conflito e disjunção existentes (...) entre as organizações (...). Os diferentes segmentos organizacionais tendem a agir segundo lógicas distintas e muitas vezes conflitantes, em função da inserção institucional que desfrutam. Disputas por espaços de poder são recorrentes, além da competição por recursos escassos. Críticas recíprocas entre os diversos segmentos organizacionais são comuns, atribuindo-se mutuamente responsabilidades por eventuais fracassos do sistema. (Batitucci, Ribeiro e Sapori, 2002:214)

No geral se percebe a existência de determinado grau de frouxa articulação no desenho institucional da segurança pública, havendo evidências empíricas abundantes nesse sentido, como apresentado por Batitucci, Ribeiro e Sapori (2002). Sabe-se não ser "possível imaginar a construção de um arranjo legal e organizacional plenamente integrado, equilibrado e harmonioso" (Batitucci, Ribeiro e Sapori, 2002:214).

Portanto, determinados arranjos explicitam elevado grau de desarticulação do sistema de segurança pública (Paixão, 1981; Costa, 2004; Lima e Proglhof, 2013), repercutindo de modo mais intenso em sua competência para realizar as atividades inerentes a si. Nesse sentido:

Quanto maior é o grau de frouxa articulação na segurança pública, menor é a capacidade de a network organizacional alcançar padrões satisfatórios de efetividade. Quando pontos de conflito e competição entre as organizações são acentuados por certos desenhos institucionais, pode-se esperar a redução da eficácia e da eficiência do sistema como um todo. Essa é [por exemplo] a realidade no Estado de Minas Gerais, devido à ausência de uma estrutura burocrática que possa estabelecer padrões mínimos de coordenação entre as organizações do aparato policial (...). (Batitucci, Ribeiro e Sapori, 2002:215)

Em face do exposto, a efetivação de políticas de combate à criminalidade em nível estadual depende do reordenamento do desenho institucional da segurança pública, com a integração de todos os órgãos (Lima e Proglhof, 2013). Corroborando essa argumentação, Batitucci, Ribeiro e Sapori (2002:215): é necessário criar "fundamentos institucionais para que decision-makers possam planejar e gerir as intervenções do executivo estadual nesse âmbito, superando a fragmentação até então vigente".

Nessa perspectiva, considera-se que uma nova arquitetura organizacional será capaz de fornecer as bases estruturais necessárias para o efetivo planejamento e gestão da política estadual de segurança pública. Fonseca (2013) mostra que essa medida amenizará a fragmentação do sistema, favorecendo a implantação de ações mais bem articuladas, bem como facilitando a prestação de contas e de respostas às mais variadas demandas sociais.

\section{Percurso metodológico}

No estudo empírico a opção pela pesquisa de natureza qualitativa ocorreu porque, diferentemente da pesquisa quantitativa, a primeira tem o condão de responder a questões muito es- 
pecíficas, preocupando-se, nas ciências sociais de modo geral e nas ciências sociais aplicadas de modo particular, com um nível de realidade que não pode ser mensurado matemática e estatisticamente. Conforme Minayo (1994:21-22, itálico nosso) a pesquisa qualitativa "trabalha com o universo de significados, motivos, aspirações, crenças, valores e atitudes, o que corresponde a um espaço mais profundo das relações, dos processos e dos fenômenos que não podem ser reduzidos à operacionalização de variáveis".

Ao tratar sobre as pesquisas em organizações, Friedberg (1995) menciona que, de acordo com os objetivos e os centros de interesse de um estudo, a organização pode ser estudada per si ou como questão introdutória para a pesquisa de um sistema maior, de que constitui um segmento consciente, formalizado e visível, ou seja, o campo das redes interorganizacionais. O autor reforça que, ao optar pela pesquisa mais ampla, se utiliza da linha de raciocínio organizacional para estudar as lógicas e os processos de estruturação do conjunto de relações existentes entre diversas organizações que atuam em uma mesma área, ou que possuam "interesses" idênticos, ou mesmo que executam as mesmas políticas públicas. Ainda, os estudos interorganizacionais conheceram florescimento extraordinário a partir da década de 1970, o que acarretou na produção de um volume de estudos bastante diversificado e rico, tanto na Europa, quanto nos Estados Unidos da América (Friedberg, 1995).

Em razão da opção por pesquisa interorganizacional é que se se definiu como método o estudo de casos múltiplos com enfoque incorporado, que é conceituado como aquele no qual ocorre a avaliação a partir de unidades de análise distintas, podendo ser utilizados, também, critérios diferenciados para sua realização. Esse tipo de estudo de caso costuma ser mais convincente, sendo uma das chaves para se construir um estudo de casos múltiplos bem-sucedido a obediência a uma lógica de replicação, lógica esta que pressupõe uma rica estrutura teórica, o que permite, a posteriori, tornar-se um instrumento para generalizar para casos novos (Yin, 2005).

Por sua vez, as unidades de análise da pesquisa são, no estado de Minas Gerais, a Secretaria de Estado de Defesa Social (Seds), a Polícia Civil (PCMG) e a Polícia Militar (PMMG) e, no Estado de São Paulo, a Secretaria de Estado de Negócios da Segurança Pública (Sesp), a Polícia Civil (PCESP), a Superintendência de Polícia Técnica Científica (SPTC) e a Polícia Militar (PMESP). As unidades de observação são os sistemas de segurança pública dos estados de Minas Gerais e São Paulo. Já os sujeitos são os integrantes das respectivas organizações de segurança pública e participantes do estudo.

De modo a representar as unidades de análise, foram selecionados até 10 sujeitos por órgão de segurança pública de cada unidade federativa, totalizando 60 entrevistados. Por se tratar de uma pesquisa qualitativa, conforme Gil (2010:91), a seleção dos sujeitos, para ser adequada, não tem a necessidade de apresentar "fundamentação matemática ou estatística, dependendo unicamente de critérios do pesquisador". Essa assertiva encontra sustentação no posicionamento de Thiollent (1981:34), que, ao tratar da seleção da população estudada, afirma que basta que esta seja "um número representativo de indivíduos, proporcional à importância das categorias que eles representam no conjunto". 
A pesquisa de campo foi cumprida nos anos de 2013 e 2014, em cada um dos estadosmembros do Brasil selecionados, em suas organizações componentes dos respectivos sistemas de segurança pública. Enfatiza-se que na citada pesquisa de campo utilizou-se de estratégias de coleta de dados, como pesquisas bibliográficas e documentais, bem como de entrevistas semiestruturadas.

Cumprida a etapa da coleta de dados, como estratégia de análise foi adotada a análise de conteúdo. Esta pode ser caracterizada como um meio para estudar as "comunicações" entre as pessoas, com ênfase para o conteúdo "das mensagens" (Bardin, 2009). Em sendo "um conjunto de técnicas", a estratégia citada é composta por alguns procedimentos indispensáveis, como a classificação dos conceitos, a codificação dos conceitos e a categorização, sendo, portanto:

Um conjunto de técnicas de análise das comunicações, visando a, por meio de procedimentos sistemáticos e objetivos de descrição do conteúdo das mensagens, obter indicadores quantitativos ou não, que permitam a inferência de conhecimentos relativos às condições de produção/recepção - variáveis inferidas — das mensagens. (Bardin, 2009:31, itálico nosso)

\section{Retórica de realidades na segurança pública}

A partir dos objetivos do estudo, analisou-se a percepção dos sujeitos integrantes dos órgãos de segurança pública e se essas percepções correspondem, ou não, aos estudos e teorias de base da pesquisa, como apresentado nas seções seguintes.

\subsection{Plano Diretor da Reforma do Aparelho do Estado}

O Plano Diretor da Reforma do Aparelho do Estado (Brasil, 1995) é fundamental para a consecução do Estado dito gerencial, implementado por meio da Emenda Constitucional noㅡ 19 (Brasil, 1998), tanto na União quanto nos demais entes federativos. Todavia, quando da realização das entrevistas, verificou-se que poucos indivíduos conhecem o documento, apesar de fazerem parte das respectivas cúpulas diretivas organizacionais, sendo tão somente um sujeito por órgão, à exceção da Secretaria de Estado dos Negócios da Segurança Pública de São Paulo, em que a maioria o conhece.

Os respondentes que conhecem o PDRAE (Brasil, 1995) percebem que este influencia as políticas públicas de segurança, conforme fragmentos de entrevistas:

O Plano (...) insere-se num contexto de ideias neoliberais, de redução do intervencionismo estatal na economia e de uma nova administração mais gerencial, o que "impactou" a segurança pública no sentido da tentativa de superação de gerenciamentos de crises por intervenções mais planejadas. Creio que este contexto foi favorável para caminharmos para um Estado, e 
uma segurança pública, mais organizado e com maior responsabilização e accountability dos gestores. (E 01)

A influência do Plano Diretor de Reforma do Estado é positiva ao trazer, ao sistema de segurança pública, a modernização das estruturas arcaicas de administração pública ainda vigentes e que travam o crescimento e o desenvolvimento das instituições, além de proporcionar aos profissionais que (re)pensem seu papel na estrutura do sistema, sendo que hoje é fundamental que todos trabalhem em uma dinâmica sistêmica, coletiva e que saibam a importância e o valor de seu trabalho, principalmente no contexto social. (E 48)

Nessa perspectiva, o desconhecimento do Plano Diretor de Reforma do Aparelho do Estado (Brasil, 1995) pela quase totalidade dos respondentes leva à concordância com o posicionamento de Pollitt e Bouckaert (2002:21) quanto à nova gestão pública, no sentido de que "fica claro que vários anos de mudança não produziram modelos consistentes". Portanto, apesar de existir um Plano bem estruturado, o PDRAE, com uma normatização robusta, a Emenda Constitucional no 19 , as entrevistas apontam para o desconhecimento de toda esta base pela maioria dos respondentes que, enfatiza-se, são responsáveis pelas políticas e estratégias de segurança pública dos estados-membros.

Quanto àqueles que conhecem o PDRAE, a ênfase é dada à gestão da segurança pública, a partir de accountability e responsiveness, do provimento logístico pela União, da descentralização e delegação, do controle e monitoramento, da modernização das estruturas e, principalmente, da gestão de recursos humanos. Nesse prisma, verifica-se não haver uma similaridade nas respostas dos entrevistados, já que cada um se posiciona de maneira diferente, em relação à influência do Plano, na segurança pública, o que novamente leva à concordância com a conclusão de Pollitt e Bouckaert (2002:8) de que "aspectos retóricos e culturais parecem desempenhar um papel importante em várias reformas do setor público", colocação que encontra respaldo especialmente na fala de um sujeito que afirma que "a reforma nunca foi implementada" (E 34).

\subsection{Plano Nacional de Segurança Pública}

No mesmo sentido do PDRAE (Brasil, 1995), o Plano Nacional de Segurança Pública (Brasil, 2003), documento de importância basilar para as políticas públicas da área no Brasil, é desconhecido pela maioria dos sujeitos, de sorte que apenas 15 dentre os 60 entrevistados o conhecem. Dentre as organizações, novamente a Secretaria de Estado dos Negócios da Segurança Pública de São Paulo se apresenta como exceção, com a maioria dos respondentes conhecendo o documento. Os entrevistados percebem que o PNSP influencia as políticas públicas de segurança da seguinte forma:

Entendo que o objetivo deste Plano é o de integrar as propostas de políticas de segurança pública, ações comunitárias e políticas sociais, ou seja, trabalhar em conjunto para que esta proposta 
seja alcançada. É uma iniciativa ousada e inovadora que propõe a integração, não somente das corporações, como também de projetos e ações preventivas e o envolvimento da sociedade na política de segurança pública. (E 02)

Acredito que o Plano Nacional de Segurança Pública busca medidas eficazes para aperfeiçoar a atuação de órgãos e instituições voltadas à segurança. (E 15)

Sim, na verdade percebo o PNSP como uma tentativa de unificar o modelo de gestão em segurança pública, em dimensão nacional. (E 30)

O Plano Nacional de Segurança Pública trata de políticas que são efetivamente necessárias à maioria dos estados brasileiros. A principal política tratada diz respeito à unificação das polícias que, no meu entendimento, não é adequada no momento, pois não há ambiente favorável para que isso ocorra no curto prazo. (E 36)

Os agentes que conhecem o Plano o percebem como integrativo, ousado e inovador, tendo por pressupostos o envolvimento da sociedade na segurança pública, uma política nacional de segurança pública, a reforma dos organismos com a criação de uma "nova polícia" e a unificação das polícias estaduais, tornando-as polícias de ciclo completo. Quanto ao aspecto integrativo do PNSP, Costa e Landim (2007) enfatizam que várias iniciativas têm sido levadas a efeito para o aumento da integração entre planejamento e gestão, com o fito de implementar a gestão por resultados nos governos, não só em âmbito federal, como também em âmbito dos estados-membros. Esse modelo tem por pressuposto tanto a estruturação das ações governamentais, em programas na busca de integração entre áreas setoriais quanto à instituição de instrumentos de contratualização, bem como a criação de sistemas de monitoramento.

\subsection{Modelos das polícias civis}

No Estado de Minas Gerais, o modelo da Polícia Civil abarca, além da polícia judiciária, a criminalística, a medicina legal e o departamento de trânsito. No que diz respeito à adequação, ou não, dos modelos das polícias civis, quanto ao cumprimento de todas as atividades, a percepção dos integrantes das organizações de segurança pública de Minas Gerais é contrária ao modelo em aplicação, na quase totalidade dos entrevistados, o que pode ser sintetizado na seguinte fala:

Apesar dos discursos em contrário, talvez "teríamos" melhores resultados em termos de redução da impunidade, através da melhoria da elucidação da autoria e materialidade de crimes, caso atividades relacionadas à perícia, exames laboratoriais e investigação criminal fossem contratadas junto ao "mercado". É só pensar no Crime Scene Investigation (CSI) norte-americano. Nem todos os especialistas são policiais, são contratados. O Estado brasileiro é muito inchado e de difícil governabilidade. (E 01) 
Em relação ao Estado de São Paulo, a Superintendência de Polícia Técnico-Científica e o Departamento de Trânsito são independentes da Polícia Civil, de modo que parte dos entrevistados afirma que os modelos são muito adequados, "cabendo, contudo, reafirmar que é fundamental a definição dos papéis de cada organização, sendo necessária uma coordenação eficiente, para que haja uma integração harmônica" (E 34), e "o modelo segmentado entre Polícia Civil, Polícia Técnico-Científica e Detran, que inclusive não está mais subordinado à SESP, é muito adequado. O que se procura é melhorar, a cada dia, a coordenação entre todos os órgãos do sistema de segurança pública do Estado de São Paulo" (E 37). Outro sujeito esclarece que "[no Estado de São Paulo] é adequado ao cumprimento da sua atividade fim, qual seja, a de polícia judiciária, (...) medicina legal, criminalística (...)” (E 33). Entretanto, a maioria dos entrevistados entende que o adequado é a existência de uma polícia única de ciclo completo, como se depreende dos fragmentos de entrevistas seguintes:

Sou favorável a uma polícia de ciclo completo, mas não vejo a Polícia Técnica e, muito menos, o Detran, como partes integrantes desta "nova polícia". Eu os vejo como colaboradores, dentro do grande sistema de segurança pública. Neste sentido, sou favorável à segmentação existente hoje entre esses órgãos [Polícia Civil, Polícia Técnico-Científica e Detran]. (E 36)

Mais uma vez acredito que o modelo ideal seria o de uma polícia única, responsável pelo ciclo completo de polícia, isso para evitar soluções de continuidade dos trabalhos policiais e bem atender à sociedade. (E 52)

Em relação à adequação, ou não, dos atuais modelos das polícias civis, necessário se faz reforçar a diferença existente entre os estados de Minas Gerais e de São Paulo. No caso mineiro, o modelo da Polícia Civil é "unificado", ou seja, estão subordinados à citada organização os seguintes órgãos: departamento de trânsito, medicina legal e criminalística. No caso paulista, existe a segmentação entre as organizações, com a existência da Polícia Civil, da Superintendência de Polícia Técnica-Científica — criminalística e medicina legal — como organizações autônomas e independentes, subordinadas diretamente à Secretaria de Estado dos Negócios da Segurança Pública, e do Departamento de Trânsito, subordinado à Secretaria de Estado de Planejamento. Verifica-se que o modelo de São Paulo é exatamente o preconizado no Plano Nacional de Segurança Pública (Brasil, 2003).

Nesse sentido, temas como diferenciação e integração fazem parte do vocabulário corrente quando se trata dos modelos segmentados de segurança pública. Quanto à diferenciação, Blau e Schoenherr (1971:16) a definem como o "número de posições diferentes e de subunidades diferentes na organização". A diferenciação é marcadamente reconhecida pela divisão das organizações, em partes, com a finalidade precípua de executarem suas atividades (Hall, 1984). A integração diz respeito à "qualidade de estado de colaboração existente entre os departamentos que são solicitados a conseguir uma unidade nos esforços pelas demandas do ambiente" (Lawrence e Lorsch, 1973:47). Os temas diferenciação e integração são mencionados como importantes quando se trata da segmentação das polícias técnico-científica e dos departamentos de trânsito, em relação às polícias civis, da extensão do modelo paulista 
aos demais estados, da criação de polícia única nos estados, da unificação dos organismos policiais, da terceirização das atividades periciais, dentre outros.

\subsection{Modelos das polícias militares}

Especificamente em relação à adequação, ou não, dos modelos das polícias militares, não se encontra consenso por parte dos sujeitos dos órgãos de segurança pública de Minas Gerais. Entretanto, a maioria entende que os modelos das polícias militares são inadequados, enfatizando que "os atuais modelos não atendem à demanda da população, [e] acredito que ainda falta muito investimento e adequação dos atuais modelos, a começar pela desmilitarização" (E 15), e que, "da mesma forma da Polícia Civil, acho que existe um acúmulo [de atividades] na Polícia Militar, que fogem da real função policial, vindo a atrapalhar o desempenho profissional" (E 22). Tais percepções são corroboradas pelo Entrevistado 14:

Acredito que os mesmos problemas expostos na resposta da questão anterior, para a Polícia Civil, ocorrem com a Polícia Militar, porém, em menor grau, devido à diferença na estrutura desta Polícia, que tem mais incentivos para capacitação e critérios claros e mais igualitários para promoção e progressão na carreira policial. (E 14)

Quanto ao Estado de São Paulo, uma parcela dos entrevistados entende que a existência de segmentação interna em sua Polícia Militar faz com que "o modelo da Polícia Militar de São Paulo [seja] diferente do modelo da Polícia Civil [paulista], possuindo uma mesma matriz, ramificada, e havendo, dentro da própria $\mathrm{PM}$, os vários comandos especializados. ${ }^{2}$ Entendo este modelo como muito coerente". Contudo, há também posicionamentos contrários, defendendo a especialização dentro de cada segmento, por entender que as chamadas "atividades especializadas, trânsito e meio ambiente, não são atividades típicas de polícia e deveriam ter direção independente. Já as atividades de polícia ostensiva e de choque, estas sim, são atividades inerentemente policiais típicas" (E 45). Este posicionamento é corroborado por outro sujeito que entende que "o modelo federal de fragmentação plena entre policiamento rodoviário ostensivo e pela polícia investigativa, executados respectivamente pela Polícia Rodoviária Federal e pela Polícia Federal, poderia ser testado em nível estadual" (E 46). Todas as assertivas anteriores diferem da percepção do Entrevistado 54:

A diversificação de atividades faz com que a Polícia Militar não tenha capacidade de articulação e de especialização para atender com excelência todas as missões que lhe são delegadas. Creio que a Polícia Militar deveria fazer o ciclo completo de polícia, e só isso. Quanto às demais atividades, outros órgãos deveriam cumpri-las. (E 54)

\footnotetext{
${ }^{2}$ Os comandos são: Ambiental, Trânsito Rodoviário, Trânsito Urbano, Choque e Rádio Patrulhamento Aéreo.
} 
Portanto, em relação à adequação, ou não, dos atuais modelos das polícias militares não se verificam grandes diferenças entre os estados de Minas Gerais e de São Paulo. Em ambos os casos as polícias militares são responsáveis pelos policiamentos de trânsito rodoviário e urbano, meio ambiente, de choque e geral, o que contraria o contido no Plano Nacional de Segurança Pública (Brasil, 2003), que prevê a transferência do trânsito urbano para os municípios.

Essa integração é sustentada por Lawrence e Lorsch (1973), que, ao conceberem o conceito, idealizaram-no como a permissão para que cada setor fosse diferente em aparência e em estrutura, de acordo com a exigência de suas funções e serviços respectivos, reforçando que a sensatez dessa medida consistia exatamente em reconhecer a possibilidade de coexistência de diferentes estruturas. Por outro lado, Bateman e Snell (2006) apontam que a integração significa que as unidades diferenciadas são agrupadas, de maneira que haja uma coordenação única, acrescentando que o conceito de integração é essencial para entender a estrutura organizacional. O tema integração é mencionado como importante quando se trata da manutenção da matriz ramificada e dos comandos especializados, da criação de polícia única nos estados, da unificação dos organismos policiais, da integração entre as especializações e otimização dos esforços operacionais, dentre outros.

\section{Considerações finais}

Consideramos que o objetivo da pesquisa foi alcançado, mediante a operacionalização da metodologia adotada. De maneira a atingir o objetivo proposto, a construção deste artigo ocorreu a partir dos seguintes pressupostos metodológicos: abordagem qualitativa, pesquisa descritiva, tendo como método o estudo de caso. As unidades de análise foram as organizações de segurança pública dos estados de Minas Gerais e de São Paulo, as unidades de observação formam os sistemas de segurança pública de estados-membros do Brasil e os sujeitos foram os integrantes das respectivas organizações de segurança pública e participantes do estudo. A coleta de dados se deu por meio de documentos e entrevistas semiestruturadas e, finalmente, a estratégia de análise dos dados foi com base na técnica de análise de conteúdo.

Em relação ao arcabouço teórico da pesquisa, fixou-se em diferentes fontes: a teoria da burocracia, que ainda é o sustentáculo da administração pública brasileira, estando fortemente arraigada na realidade das organizações de segurança pública; o modelo da nova gestão pública, que se situa como "tipo ideal" weberiano a ser atingido pelos sistemas de segurança pública dos estados-membros; a estrutura das organizações, que norteou a pesquisa, já que o foco foram os modelos estruturais de segurança pública; e a administração pública e a segurança pública, que complementaram o embasamento teórico, de certa maneira "unindo" a teoria da burocracia com o modelo da nova gestão pública.

No que diz respeito ao Plano Diretor da Reforma do Aparelho do Estado (Brasil, 1995), sua aplicação na área de segurança pública é percebida de maneiras diferentes, pelos entrevistados do estado de Minas Gerais em relação aos entrevistados do estado de São Paulo. De modo geral, os respondentes do sistema de segurança pública mineiro suscitam não conhecer 
o PDRAE, havendo somente algumas exceções em cada organização; os indivíduos que se situam como exceções entendem que o "tipo ideal" de aplicabilidade do PDRAE redundará em avanços na gestão dos órgãos de segurança pública, na inovação gerencial e na maior responsabilização dos gestores e consequente accountability. Já os entrevistados do sistema de segurança pública paulista se dividem entre conhecedores do PDRAE - no caso, os membros da Secretaria de Segurança Pública em praticamente sua totalidade, que enfatizam que a reforma prevista na Emenda Constitucional no 19 nunca foi implementada e a previsão do papel majoritariamente regulador e fiscalizador do Estado - , e aqueles que desconhecem o Plano, que são a maioria dos integrantes das diversas organizações policiais; o entendimento é que o "tipo ideal" de aplicabilidade do PDRAE redundará na reforma em um conceito macroestrutural, na descentralização e delegação, no controle e monitoramento, em metas e indicadores e em melhoria na gestão de recursos humanos. Portanto, pode-se concluir que, quanto à área de segurança pública nos estados-membros brasileiros, o contido no Plano Diretor da Reforma do Aparelho do Estado se apresenta como retórica, não se percebendo efetivamente sua utilização na realidade, havendo uma dissociação entre o contido no Plano e na Emenda Constitucional no 19 e a percepção dos entrevistados que, reforça-se, integram os níveis diretivos das organizações de segurança pública.

De mesmo modo que no caso do PDRAE, no que tange ao Plano Nacional de Segurança Pública (Brasil, 2003), a sua aplicação também é percebida de maneiras diferentes pelos entrevistados do estado de Minas Gerais em relação aos entrevistados do estado de São Paulo. De modo geral, assim como ocorrido com o PDRAE, os respondentes do sistema de segurança pública mineiro sinalizam não conhecer o PNSP, havendo somente algumas exceções em cada organização; os indivíduos que se situam como exceções entendem que o "tipo ideal" de aplicabilidade do PNSP redundará em uma política nacional de segurança pública, na reforma das organizações policiais, na unificação dos órgãos de segurança pública e na melhoria da prevenção com o envolvimento da sociedade. Já os entrevistados do sistema de segurança pública paulista, assim também como ocorrido com o PDRAE, se dividem entre conhecedores do PNSP — no caso os membros da Secretaria de Segurança Pública em praticamente sua totalidade, que enfatizam o fato de o Plano haver sido proposto a partir da experiência do Estado de São Paulo, com a finalidade de se criar um "novo modelo" de polícia - , e aqueles que desconhecem o Plano, que representam um número razoável de integrantes das diversas organizações policiais; o entendimento é que o "tipo ideal" de aplicabilidade do PNSP redundará na criação de um "novo modelo de polícia", diferente das atuais polícias civis e militares; no aperfeiçoamento do sistema de segurança pública dos estados-membros; na universalização das ações e gestão e na captação de recursos da União. Portanto, pode-se concluir que o contido no Plano Nacional de Segurança Pública também se apresenta como retórica, não se percebendo efetivamente sua utilização na realidade, à exceção de questões pontuais, de sorte que há uma clara dissociação entre o contido no Plano e a percepção dos entrevistados.

No que diz respeito ao modelo de estrutura de segurança pública adotado no estado de Minas Gerais, percebe-se que é "fragmentado" em termos macroestrutural e "integrado" 
em termos microestrutural. Em termos macro há quatro órgãos em nível de primeiro escalão governamental: Secretaria de Estado de Defesa Social, Polícia Civil, Polícia Militar e Corpo de Bombeiros Militar. Em termos micro, especificamente em relação às polícias, o modelo da Polícia Civil engloba as atividades de polícia judiciária e investigativa, de polícia técnica - Instituto de Criminalística, Instituto Médico Legal e Instituto de Identificação - e o Departamento de Trânsito, utilizando-se neste caso da departamentalização funcional, havendo um delegado na direção de cada órgão especializado. Já a Polícia Militar engloba todas as atividades de polícia preventiva e ostensiva - geral, meio ambiente, trânsito urbano, trânsito rodoviário e repressão — , utilizando-se neste caso principalmente da departamentalização geográfica, já que as atividades mencionadas são distribuídas no território mineiro, ficando todas elas subordinadas a um coronel comandante regional. Observa-se, também, que os modelos mencionados, conforme consta do Plano Nacional de Segurança Pública (Brasil, 2003), permanecem os mesmos desde a sua criação, com uma Secretaria de Estado e duas polícias autônomas e distanciadas entre si, ou seja, não há que se falar na utilização de preceitos do modelo da nova gestão pública no que tange à estrutura do sistema de segurança pública mineiro. Além do contido no PNSP, esta também é a percepção dos investigados que, em sua maioria, enfatizam a necessidade de mudanças urgentes.

No que tange ao modelo de estrutura de segurança pública adotado no Estado de São Paulo, de maneira diametralmente oposta ao modelo mineiro, o modelo paulista é relativamente "unificado" em termos macroestrutural e "segmentado" em termos microestrutural. Em termos macro há tão somente um órgão em nível de primeiro escalão governamental, que é a Secretaria de Estado dos Negócios de Segurança Pública, estando todos os demais órgãos subordinados a esta, ou seja, suas polícias fazem parte do segundo escalão governamental. Em termos micro, especificamente em relação às polícias, existem a Polícia Civil, que executa as atividades de polícia judiciária e investigativa, a Superintendência de Polícia Técnico-Científica, que executa as atividades relativas à criminalística e à medicina legal, e a Polícia Militar, que executa as atividades preventivas e ostensivas, utilizando-se, portanto, da departamentalização funcional, havendo um responsável, perante o secretário de Segurança Pública, na direção de cada organização policial estadual. Especificamente no caso da Polícia Militar, esta engloba todas as atividades de polícia preventiva e ostensiva — geral, meio ambiente, trânsito urbano, trânsito rodoviário, repressão, além do corpo de bombeiros —, utilizando-se neste caso, ao contrário de Minas Gerais, principalmente da departamentalização funcional, já que as atividades mencionadas são distribuídas por tipologia de atividades, ficando cada uma delas subordinada a um coronel comandante da respectiva área especializada. No caso de São Paulo, além da existência de uma Secretaria de Estado à qual estão subordinadas as polícias estaduais, outra diferença em relação ao sistema de segurança pública mineiro é o fato de que existem três organizações policiais. Neste sentido, nota-se consonância com o contido no Plano Nacional de Segurança Pública (Brasil, 2003), de sorte que, pontualmente, há avanços estruturais que são previstos na própria teoria da burocracia (Hall, 1984). Esta também é a percepção dos respondentes, bem como a previsão no mencionado Plano. 
Entende-se que a presente pesquisa supre algumas lacunas dos estudos sobre a segurança pública sob a ótica das ciências administrativas e da gestão. A partir do uso de metodologia rigorosa foram estudadas as percepções dos agentes acerca de algumas inquietações relacionadas com os modelos dos órgãos de segurança pública. Ainda, realizou-se profunda e ampla revisão bibliográfica dos temas burocracia, modelo da nova gestão pública, administração pública, estruturas das organizações e segurança pública, o que certamente contribuirá para a realização de trabalhos futuros tanto em nível de pós-graduação quanto de graduação, especialmente relacionados com a segurança pública.

Quanto às limitações da pesquisa, o fato de se optar pela realização de estudos de casos de organizações de segurança pública em dois estados-membros brasileiros, Minas Gerais e São Paulo, já restringe o estudo. Como é da natureza do método escolhido, necessário se faz considerar eventuais vieses devido à capacidade do pesquisador de interpretar as declarações dos entrevistados e de analisar os documentos disponíveis. Finalmente, há que se considerar o histórico dos entrevistados nas organizações, suas motivações e, também, suas capacidades de interpretar e enunciar os fatos. Além disso, informações consideradas sigilosas podem não ter sido apresentadas aos pesquisadores.

Finalmente, em razão de outras possibilidades de estudos que não foram tratadas nesta pesquisa, sugere-se sua ampliação a partir de novos estudos com foco em: (1) análise dos atuais modelos de segurança pública, com a segmentação entre as polícias civis e militares; (2) análise dos atuais modelos militarizados das polícias estaduais; (3) criação de polícias estaduais de ciclo completo; (4) criação de "nova polícia", diferente das atuais polícias civis e militares; (5) terceirização de atividades não policiais, a exemplo das tarefas realizadas nos departamentos de trânsito e nas polícias técnico-científicas; e (6) utilização de métodos quantitativos em pesquisas nas organizações de segurança pública, especificamente relativas a inquietações vinculadas às ciências administrativas e da gestão.

\section{Referências}

ABRUCIO, Fernando L. Os avanços e os dilemas do modelo pós-burocrático: a reforma da administração pública à luz da experiência internacional recente. In: BRESSER-PEREIRA, Luiz C.; SPINK, Peter (Org.). Reforma do estado e administração pública gerencial. 7. ed. São Paulo: FGV, 2006. p. 173-199.

AUCOIN, Peter. Administrative reform in public management: paradigms, principles, paradox's and pendulums. Cambridge: Cambridge University Press, 1990.

BARDIN, Laurence. Análise de conteúdo. Lisboa: Almedina, 2009.

BATEMAN Thomas S.; SNELL, Scott A. Administração: novo cenário competitivo. São Paulo: Atlas, 2006. 
BATITUCCI, Eduardo C.; RIBEIRO, Ludmila M. L.; SAPORI, Luís F. Diretrizes para uma política de segurança pública em Minas Gerais. In: MINAS GERAIS. Banco de Desenvolvimento de Minas Gerais. Minas Gerais do século XXI. Belo Horizonte: Rona, 2002. p. 197-216.

BERGER, Peter; LUCKMANN, Thomas. The social construction of reality. Nova York: Garden City, 1967.

BLAU, Peter M.; SCHOENHERR, Richard. The structure of organizations. Nova York: Basic, 1971.

BRASIL. Câmara dos Deputados. Considerações sobre a criação de novos órgãos policiais. Brasília: Gráfica da Câmara dos Deputados, 2009.

BRASIL. Constituição da República Federativa do Brasil. Brasília: Gráfica do Senado, 1988.

BRASIL. Decreto n. 5.289, de 29 de novembro de 2004. Cria a Força Nacional de Segurança Pública (FNSP). Brasília: Imprensa Nacional, 2004.

BRASIL. Emenda Constitucional n. 19. Brasília: Gráfica do Senado, 1998.

BRASIL. Lei n. 11.530, de 24 de outubro de 2007. Institui o Programa Nacional de Segurança Pública com Cidadania (Pronasci). Brasília: Imprensa Nacional, 2007.

BRASIL. Ministério da Administração Federal e Reforma do Estado. Plano Diretor da Reforma do Aparelho do Estado. Brasília: Imprensa Nacional, 1995.

BRASIL. Ministério da Administração Federal e Reforma do Estado. Programa da Qualidade e Participação na Administração Pública. Brasília: Imprensa Nacional, 1997.

BRASIL. Ministério da Justiça, Secretaria Nacional de Segurança Pública. Plano Nacional de Segurança Pública. Brasília: Imprensa Nacional, 2003.

BRESSER-PEREIRA, Luiz C. A reforma do Estado dos anos 90: lógica e mecanismos de controle. Cadernos MARE da Reforma do Estado. Brasília: Ministério da Administração Federal e Reforma do Estado, 1997.

BRESSER-PEREIRA, Luiz C. A reforma do Estado para a cidadania: a reforma gerencial brasileira na perspectiva internacional. São Paulo: Ed. 34 Ltda., 1998.

BRESSER-PEREIRA, Luiz C. Da administração pública burocrática à gerencial. In: BRESSER-PEREIRA, Luiz C.; SPINK, Peter (Org.). Reforma do Estado e administração pública gerencial. 6. ed. São Paulo: Ed. FGV, 2006. p. 274-296.

BRESSER-PEREIRA, Luiz C. Reforma da nova gestão pública: agora na agenda da América Latina, no entanto... Revista do Serviço Público, v. 53, n. 2, p. 5-28, abr./jun. 2002.

BRESSER-PEREIRA, Luiz C. Uma nova gestão para um novo Estado: liberal, social e republicano. Revista do Serviço Público, v. 52, n. 1, p. 5-24, jan./mar. 2001.

BRESSER-PEREIRA, Luiz C.; SPINK, Peter. Construindo o Estado republicano: democracia e reforma da gestão pública. Rio de Janeiro: FGV, 2009. 
COSTA, Arthur T. M. As reformas nas polícias e seus obstáculos: uma análise comparada das interações entre a sociedade civil, a sociedade política e as polícias. Civitas: Revista de Ciências Sociais, v. 8, n. 3, p. 409-427, set./dez. 2008.

COSTA, Arthur T. M. Entre a lei e a ordem: violência e reforma nas polícias. Rio de Janeiro: FGV, 2004.

COSTA, Frederico L. C.; LANDIM, Maria C. Gestão pública nos governos subnacionais no Brasil: avanços, omissões e perspectivas. In: CONGRESO INTERNACIONAL DEL CLAD SOBRE LA REFORMA DEL ESTADO Y DE LA ADMINISTRACIÓN PÚBLICA, XII, 2007, Santo Domingo.

CROZIER, Michel. O fenômeno burocrático. Brasília: Universidade de Brasília, 1981.

FARNHAN, David; HORTON, Sylvia. Managing people in public services. Londres: The Macmillan Press Ltd., 1996.

FLYNN, Norman. Public sector management: the future of public management. Londres: Harvest Wheatsheaf, 1990.

FONSECA, Jeferson A. Retórica e realidade na segurança pública: estudo das estruturas dos sistemas de segurança pública dos estados de Minas Gerais e São Paulo. Tese (doutorado em administração) — Universidade Federal de Minas Gerais, Belo Horizonte, 2013.

FRIEDBERG, Erhard. Organização. In: BOUDON, Raymond (Org.). Tratado de sociologia. Rio de Janeiro: Jorge Zahar Ed., 1995. p. 375-412.

GIL, Antonio C. Métodos e técnicas de pesquisa social. 6. ed., 3. reimp. São Paulo: Atlas, 2010.

GOODSELL, Charles. Reinvent government or rediscover it? Public Administration Review, v. 53, n. 1, p. 85-87, jan./fev. 1993.

GOULDNER, Alvin W. Conflitos na teoria de Weber. In: CAMPOS, Edmundo (Org.). Sociologia da burocracia. Rio de Janeiro: Zahar, 1966. p. 54-61.

HALL, Richard H. O conceito de burocracia: uma contribuição empírica. In: CAMPOS, Edmundo (Org.). Sociologia da burocracia. Rio de Janeiro: Zahar, 1966. p. 28-44.

HALL, Richard H. Organizações: estrutura e processos. Tradução de Wilma Ribeiro. São Paulo: Prentice Hall do Brasil, 1984.

HOOD, Christopher. A public management for all seasons? Public Administration, v. 69, n. 3, p. 32-35, mar. 1991.

HOOD, Christopher. Economic rationalism in public management: from progressive public administration to the new public management? In: HOOD, Christopher. Explaining economic policy reversals. Buckingham: Open University Press, 1994. p. 472-488.

JONES, Lawrence R.; THOMPSON, Fred. Um modelo para a nova gerência pública. Revista do Serviço Público, v. 51, n. 1, p. 41-80, jan./mar. 2000. 
LAWRENCE, Paul R.; LORSCH, Jay W. As organizações e o ambiente. Petrópolis: Vozes, 1973.

LEITE, Nildes R. P.; ALBUQUERQUE, Lindolfo G.; KNIESS, Cláudia T. Reflexões sobre comprometimento e gestão de pessoas em estruturas organizacionais inovativas e remotas. Revista de Administração e Inovação, São Paulo, v. 7, n. 4, p. 87-112, out./dez. 2010.

LIMA, Renato S. de; PROGLHOF, Patrícia N. (Re) estruturação da segurança pública no Brasil. In: MINGARDI, Guaracy (Org.). Políticas de segurança: os desafios de uma reforma. São Paulo: Fundação Perseu Abramo, 2013. p. 31-42.

MERTON, Robert K. Sociologia, teoria e estrutura. São Paulo: Mestre Jou, 1968.

MINAS GERAIS. Polícia Militar de Minas Gerais. Diagnóstico de segurança pública n. 01/2007: a gênese dos órgãos policiais do Brasil. Belo Horizonte: EMPM1, 2007.

MINAYO, Maria C. S. (Org.). Pesquisa social: teoria, método e criatividade. 7. ed. Petrópolis: Vozes, 1994.

OSBORNE, David; GAEBLER, Ted. Reinventing government: how the entrepreneurial spirit is transforming the public sector from schoolhouse to statehouse, city hall to the Pentagon. Reading, MA: Addison-Wesley, 1992.

PAIXÃO, Antônio L. A distribuição de segurança pública e a organização policial. In: ENCONTRO DA ASSOCIAÇÃO NACIONAL DE PÓS-GRADUAÇÃO E PESQUISA EM CIÊNCIAS SOCIAIS, V, GT Organizações e Sociedade, 1981, Nova Friburgo.

PAULA, Ana P. P. Por uma nova gestão pública: limites e potencialidades da experiência contemporânea. Rio de Janeiro: FGV, 2005.

PERROW, Charles B. Complex organizations: a critical essay. Nova York: McGraw-Hill, 1972.

POLLITT, Christopher. Managerialism and the public services: the Anglo-American experience. Oxford: Basil Blackwell, 1990.

POLLITT, Christopher; BOUCKAERT, Geert. Avaliando reformas da gestão pública: uma perspectiva internacional. Revista do Serviço Público, v. 53, n. 3, p. 5-31, jul./set. 2002.

RANSON, Stewart; HINNINGS, Robert; GREENWOOD, Royston. The structuring of organizational structures. Administrative Science Quarterly, v. 25, n. 1, p. 1-17, mar. 1980.

SLOMSKI, Valmor et al. Governança corporativa e governança na gestão pública. São Paulo: Atlas, 2008.

THIOLLENT, Michel. Crítica metodológica, investigação social e enquete operária. São Paulo: Pólis, 1981.

UDY JR., Stanley H. "Burocracia" e "racionalidade" na teoria weberiana da organização: um estudo empírico. In: CAMPOS, Edmundo (Org.). Sociologia da burocracia. Rio de Janeiro: Zahar, 1966. p. 45-53. 
VASCONCELLOS, Eduardo P. G.; HEMSLEY, James R. Estrutura das organizações: estruturas tradicionais, estruturas para inovação, estrutura matricial. São Paulo: Pioneira Thomson Learning, 1986.

WEBER, Max. Ensaios de sociologia: burocracia. Rio de Janeiro: Zahar, 1967.

YIN, Robert K. Estudo de caso: planejamento e métodos. 3. ed. Porto Alegre: Bookman, 2005.

Jeferson A. Fonseca é doutor em administração e professor da Cepead/Face da Universidade Federal de Minas Gerais (UFMG). Mestre em administração (UFMG) e em administração pública (Escola de Governo da Fundação João Pinheiro). E-mail: jeferson.ufmg@gmail.com.

Luciano Z. Pereira é doutor em administração pela Universidade Federal de Minas Gerais (UFMG). Professor aposentado da UFMG. Professor titular e pesquisador do Programa de Mestrado Acadêmico em Administração da Faculdade Novos Horizontes. E-mails: lzille@face.ufmg.br; luciano.zille@unihorizontes.br.

Carlos A. Gonçalves é doutor em administração pela Universidade de São Paulo (USP). Mestre em ciências da computação pela Universidade Federal de Minas Gerais (UFMG). Professor e pesquisador da Fumec e da UFMG. E-mail: carlos@face.ufmg.br. 